www.nature.com/jp

\title{
EDITORIAL
}

\section{TLRs, SNPs and VLBWs: Oh My!}

\author{
Journal of Perinatology (2013) 33, 745-747; doi:10.1038/jp.2013.94
}

Elegant sensing mechanisms have evolved to facilitate detection of potentially pathogenic microorganisms. Since Charles Janeway predicted their existence, ${ }^{1}$ multiple classes of pathogen recognition receptors (PRRs) have been discovered that serve as detectors of microbial products, including cell wall and membrane components, flagellum, nucleic acids and carbohydrates. Perhaps no class of PRRs is as well characterized and more widespread in publications across multiple scientific disciplines than the Toll-like receptors (TLRs). The tale of TLRs is an exciting story that has generated two Nobel Prizes in Physiology or Medicine (1995, 2011). It began with the discovery of Toll protein as an important regulator of Drosophilia embryogenesis in 1985 by Christiane Nüsslein-Vollhard ${ }^{2,3}$ (Nobel Prize 1995). Then Bruno Lemaitre in the laboratory of Jules Hoffman discovered that flies deficient in Toll were more susceptible to fungal infection, thereby establishing the critical connection of Toll and immune function. ${ }^{4}$ In 1997, a human variant of Toll ('Toll-like') was identified by Ruslan Medzhitov and Charles Janeway, Jr, as a type I transmembrane protein receptor with an extracellular leucine-rich repeat domain and a cytoplasmic domain homologous to the human interleukin (IL)-1 receptor. ${ }^{5}$ The subsequent cloning of TLR4 by Bruce Beutler ${ }^{6}$ (Nobel Prize 2011) and multiple other landmark studies that have identified TLRs as key innate immune system receptors established TLRs as a permanent and critical part of pathogen recognition. ${ }^{7}$ Ten TLRs have been described in humans, each for the most part with a specific agonist that triggers activation of second messenger signaling and ultimately cellular activation along with the production of inflammatory mediators (Figure 1a).

Single-nucleotide polymorphisms (SNPs, pronounced 'snips') are DNA sequence variations that occur when a single nucleotide in the genome sequence is altered (Figure 1b). Common SNPs occur in $>1 \%$ of the population, account for $\sim 90 \%$ of all human genetic variation, and may happen every 100-300 bases anywhere

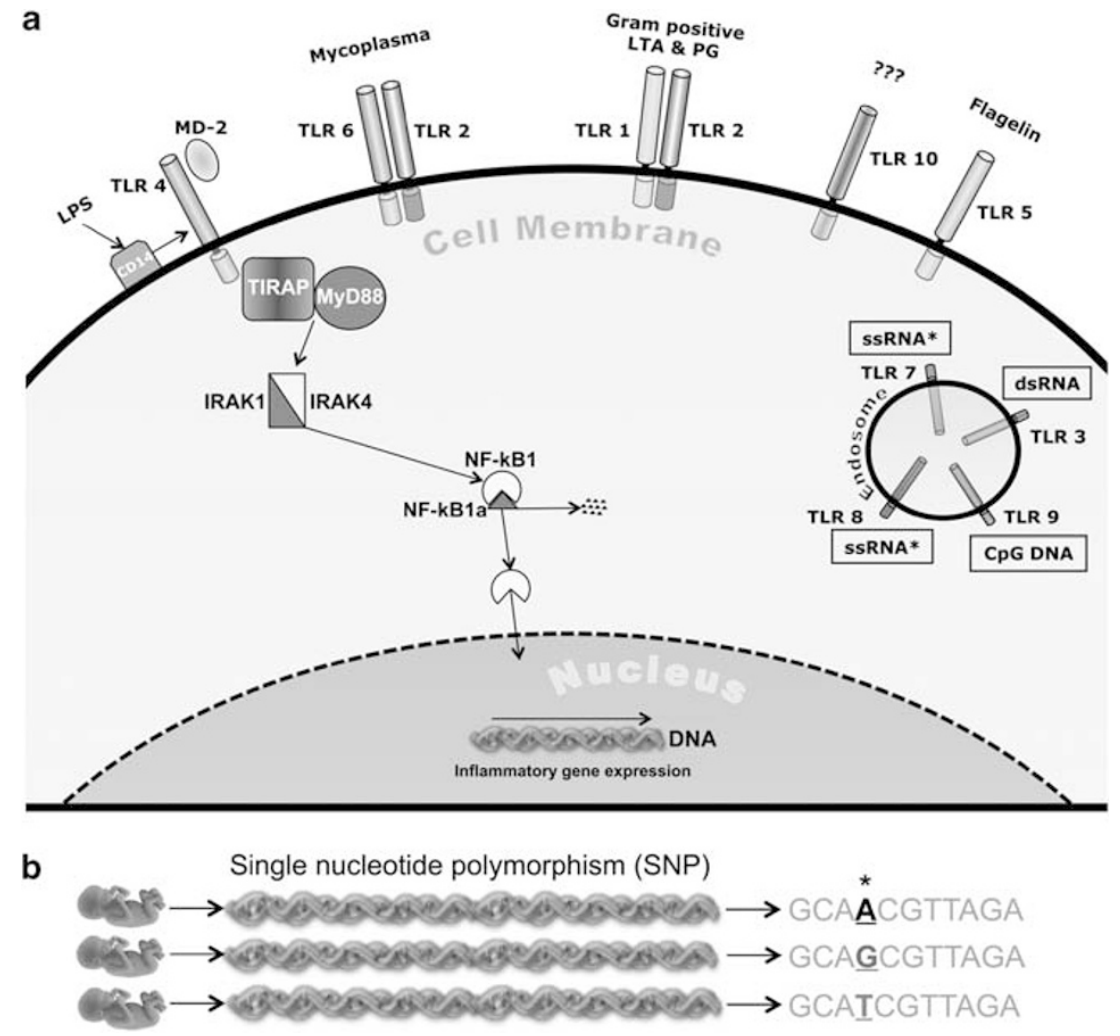

Figure 1. (a) Toll-like receptors are present on the cell membrane and within endosomes. Selected intracellular second messenger signaling molecules examined in the Sampath et. al. ${ }^{29}$ study are shown. Following stimulation of TLR4, a cascade of intracellular second messengers (TIRAP, MyD88, IRAK1, IRAK4) ultimately leads to destruction of the inhibitor NF- $\kappa B 1 a$ (blue triangle), which allows NF- $\mathrm{kB} 1$ to enter the nucleus and stimulate transcription of inflammatory gene products such as cytokines and chemokines. (b). Single-nucleotide polymorphisms (SNPs) are variations in the DNA sequence. For each infant, there is a single-nucleotide variation (represented by *) in the hypothetical gene sequence shown. DNA, deoxyribonucleic acid; IRAK1, interleukin-1 Receptor-Associated Kinase 1; IRAK4, interleukin-1 Receptor-Associated Kinase 4; LPS, lipopolysaccharide; LTA, lipotechoic acid; MD-2, myeloid differentiation factor 2; MyD88, myeloid differentiation factor 88;

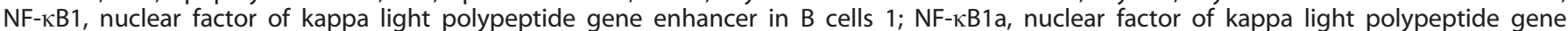
enhancer in B cells inhibitor alpha (also called IКB $\alpha$ ); PG, peptidoglycan; ssRNA, single-stranded ribonucleic acid; TIRAP, toll-interleukin-1 receptor domain containing adaptor protein; TLR, Toll-like receptor. *These TLRs may also respond to synthetic agonists including imidazoquinolines and nucleoside analogs. 
along the length of the human genome. ${ }^{8}$ Because only $\sim 5 \%$ of human DNA represents protein-coding genes, most SNPs naturally occur in noncoding regions of the genome. Of note, with the exceptions of the amino acids methionine and tryptophan that have a single codon, all other amino acids manifest codon redundancy (multiple codons lead to translation of the same amino acid). Thus, a SNP may produce no overt effects even if it occurs within a gene. However, a SNP may result in a clinical phenotype (for example, altered disease risk or response to medication) if it occurs within a specific gene, including key regulatory elements (for example, transcription factor). Because TLRs and the downstream molecules that follow TLR stimulation have an essential role in pathogen recognition and response, SNPinduced alterations in their structure may adversely affect function and the capability of the host to respond to infectious challenge.

This month in the Journal, Dr Sampath et al. ${ }^{9}$ report the impact of nine functional TLR SNPs (TLRs 2, 4, 5, 9, and downstream signaling genes including Interleukin-1 Receptor-Associated Kinase 1 (IRAK1), toll-interleukin-1 receptor domain containing adaptor protein (TIRAP), and nuclear factor of kappa light polypeptide gene enhancer in B-cells 1 (NF-KB1), and its inhibitor nuclear factor of kappa light polypeptide gene enhancer in B-cells inhibitor, alpha

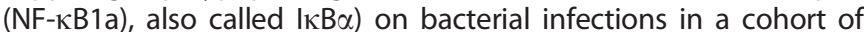
408 VLBW infants. Importantly, the authors performed an a priori power calculation to determine the sample size (400 infants) required to detect a 12 to $15 \%$ difference in SNP prevalence between groups. Ninety infants had culture-positive infections (40 with bacteremia, 26 tracheal infections, 3 urinary tract infections and 21 multi-site infections). After controlling for confounders, the presence of a TLR4 SNP was associated with increased risk of Gram-negative infections (odds ratio $=3.1$ ). Interestingly, the presence of the TLR5 variant was associated with increased circulating white blood cell counts.

Several recent neonatal studies have demonstrated an association between small variations in DNA, specifically SNPs, and infection development and outcomes. ${ }^{10-14}$ In the Abu-Maziad et al. ${ }^{10}$ study, several SNPs were identified as potentially important risk factors for the development of infection in preterm $(<37$ weeks completed gestation) infants. These included mediators of pathogen recognition (TLR2, TLR5), mechanisms of host defense against bacteria (phospholipase A2) and a critical antiinflammatory cytokine (IL-10). SNPs are associated with abnormal host responses to infectious challenges, risk of the development of infection and outcomes following infection in other neonatal populations. ${ }^{11-13,15-17} \mathrm{~A}$ recent twin study that assessed frequency of infections among mono- and di-zygotic prematurely born twins identified that $49.0 \%(P=0.002)$ of the variance in susceptibility to late-onset sepsis was due to genetic factors alone, and $51.0 \%(P=0.001)$ was the result of residual environmental factors to variation in infection risk attributable to inherited factors. ${ }^{18}$

SNPs in TLRs are associated with increased risk for infection in adults $^{19-22}$ and in children ${ }^{23-25}$ but have been less well characterized in neonates. Specific SNPs are associated with hearing loss after meningitis, ${ }^{26}$ disease progression in HIVinfected children, ${ }^{27}$ the effects of vitamin A supplementation, 28 and atopy. ${ }^{29}$ In addition to their present report, Dr Sampath et al. ${ }^{9}$ have also recently reported that a TLR5 SNP was associated with severe bronchopulmonary dysplasia. ${ }^{30}$ The frequency of TLR4 SNPs differs among African, Asian and European populations that may become important for stratifying disease risk. ${ }^{31}$ Coding modifications for upstream and downstream TLR signaling molecules may also impact risk of infection. Genetic variations in the lipopolysaccharide (LPS) coreceptor CD14, LPS binding protein (which binds to intravascular LPS and facilitates its attachment to CD14), and myeloid differentiation-2 (a small protein that associates with TLR4 to enhance LPS signaling) are associated with increased risk for sepsis in adults. ${ }^{32-35}$ Polymorphisms in downstream (post-TLR activation) intracellular signaling molecules including myeloid differentiation factor $88^{36}$ IL-1-receptor-associated kinase 4 (IRAK4) ${ }^{37}$ and NF- $\kappa B$ essential modulator (NEMO) $)^{38}$ are associated with invasive bacterial infection in older populations.

As with any diagnostic or prognostic test, studies that have identified SNPs associated with clinical conditions have limitations and important issues for consideration. ${ }^{39}$ Studies must be powered appropriately and employ rigorous statistical approaches to avoid type I and II errors. The results from well-designed and appropriately powered genome-wide association studies that identify SNPs could have a significant impact in neonatology. The presence of SNPs may inform us which women may have an increased risk of preterm birth, chorioamnionitis, pregnancyinduced hypertension and so on before they become pregnant and/or deliver preterm. After birth, specific SNPs may help us identify neonates at highest risk for the development of devastating complications of prematurity including sepsis, bronchopulmonary dysplasia, retinopathy or prematurity, white matter damage, necrotizing enterocolitis and poor neurodevelopmental outcomes. SNPs may help to stratify patients, so risk may be evenly matched in future interventional randomized clinical trials. The impact of SNPs in the field of pharmacogenetics is an area of intense research and may lead to more effective and personalized treatment strategies and a reduction in drug-related complications of treatment. The discovery of genetic variations associated with infection and other adverse outcomes in neonatology is in its early infancy. Dr Sampath et al. ${ }^{9}$ have illustrated how these personal molecular data may be translated from the bench to bedside to help us improve care for our smallest infants.

\section{JL Wynn \\ Division of Neonatal-Perinatal Medicine, Department of Pediatrics Vanderbilt University Medical Center, Nashville, TN, USA E-mail: james.wynn@vanderbilt.edu}

\section{REFERENCES}

1 Janeway Jr CA. Approaching the asymptote? Evolution and revolution in immunology. Cold Spring Harb Symp Quant Biol 1989; 54(Part 1): 1-13.

2 Anderson KV, Bokla L, Nusslein-Volhard C. Establishment of dorsal-ventral polarity in the Drosophila embryo: the induction of polarity by the Toll gene product. Cell 1985; 42: 791-798

3 Anderson KV, Jurgens G, Nusslein-Volhard C. Establishment of dorsal-ventral polarity in the Drosophila embryo: genetic studies on the role of the Toll gene product. Cell 1985; 42: 779-789.

4 Lemaitre B, Nicolas E, Michaut L, Reichhart JM, Hoffmann JA. The dorsoventral regulatory gene cassette spatzle/Toll/cactus controls the potent antifungal response in Drosophila adults. Cell 1996; 86: 973-983.

5 Medzhitov R, Preston-Hurlburt $\mathrm{P}$, Janeway Jr. CA. A human homologue of the Drosophila Toll protein signals activation of adaptive immunity. Nature 1997; $\mathbf{3 8 8}$ : 394-397.

6 Poltorak A, He X, Smirnova I, Liu MY, Van Huffel C, Du X et al. Defective LPS signaling in $\mathrm{C} 3 \mathrm{H} / \mathrm{HeJ}$ and $\mathrm{C} 57 \mathrm{BL} / 10 \mathrm{ScCr}$ mice: mutations in Tlr4 gene. Science 1998; 282: 2085-2088.

7 Kawai T, Akira S. The role of pattern-recognition receptors in innate immunity: update on Toll-like receptors. Nat Immunol 2010; 11: 373-384.

8 Abecasis GR, Auton A, Brooks LD, DePristo MA, Durbin RM, Handsaker RE et al. An integrated map of genetic variation from 1,092 human genomes. Nature 2012; 491: 56-65.

9 Sampath V, Mulrooney NP, Garland JS, He J, Patel AL, Cohen JD et al. Toll-like receptor genetic variants are associated with Gram-negative infections in VLBW infants. J Perinatol 2013 (in issue)

10 Abu-Maziad A, Schaa K, Bell EF, Dagle JM, Cooper M, Marazita ML et al. Role of polymorphic variants as genetic modulators of infection in neonatal sepsis. Pediatr Res 2010; 68: 323-329.

11 Koroglu OA, Onay H, Erdemir G, Yalaz M, Cakmak B, Akisu M et al. Mannosebinding lectin gene polymorphism and early neonatal outcome in preterm infants. Neonatology 2010; 98: 305-312. 
12 van der Zwet WC, Catsburg A, van Elburg RM, Savelkoul PH, VandenbrouckeGrauls CM. Mannose-binding lectin (MBL) genotype in relation to risk of nosocomial infection in pre-term neonates in the neonatal intensive care unit. Clin Microbiol Infect 2008; 14: 130-135.

13 Baier RJ, Loggins J, Yanamandra K. IL-10, IL-6 and CD14 polymorphisms and sepsis outcome in ventilated very low birth weight infants. BMC Med 2006; 4: 10.

14 Hedberg CL, Adcock K, Martin J, Loggins J, Kruger TE, Baier RJ. Tumor necrosis factor alpha-308 polymorphism associated with increased sepsis mortality in ventilated very low birth weight infants. Pediatr Infect Dis J 2004; 23: 424-428.

15 Szebeni B, Szekeres R, Rusai K, Vannay A, Veres G, Treszl A et al. Genetic polymorphisms of CD14, toll-like receptor 4, and caspase-recruitment domain 15 are not associated with necrotizing enterocolitis in very low birth weight infants. $J$ Pediatr Gastroenterol Nutr 2006; 42: 27-31.

16 Harding D. Impact of common genetic variation on neonatal disease and outcome. Arch Dis Child Fetal Neonatal Ed 2007; 92: F408-F413.

17 Lavoie PM, Pham C, Jang KL. Heritability of bronchopulmonary dysplasia, defined according to the consensus statement of the national institutes of health. Pediatrics 2008; 122: 479-485.

18 Bizzarro MJ, Jiang Y, Hussain N, Gruen JR, Bhandari V, Zhang H. The impact of environmental and genetic factors on neonatal late-onset sepsis. $J$ Pediatr 2011; 158: $234-238$.

19 Bochud PY, Chien JW, Marr KA, Leisenring WM, Upton A, Janer M et al. Toll-like receptor 4 polymorphisms and aspergillosis in stem-cell transplantation. $N$ Engl J Med 2008; 359: 1766-1777.

20 Wurfel MM, Gordon AC, Holden TD, Radella F, Strout J, Kajikawa O et al. Toll-like receptor 1 polymorphisms affect innate immune responses and outcomes in sepsis. Am J Respir Crit Care Med 2008; 178: 710-720.

21 Agnese DM, Calvano JE, Hahm SJ, Coyle SM, Corbett SA, Calvano SE et al. Human toll-like receptor 4 mutations but not CD14 polymorphisms are associated with an increased risk of gram-negative infections. J Infect Dis 2002; 186: 1522-1525.

22 Lorenz E, Mira JP, Cornish KL, Arbour NC, Schwartz DA. A novel polymorphism in the toll-like receptor 2 gene and its potential association with staphylococcal infection. Infect Immun 2000; 68: 6398-6401.

23 Zhang SY, Jouanguy E, Ugolini S, Smahi A, Elain G, Romero P et al. TLR3 deficiency in patients with herpes simplex encephalitis. Science 2007; 317: 1522-1527.

24 Mockenhaupt FP, Cramer JP, Hamann L, Stegemann MS, Eckert J, Oh NR et al. Tolllike receptor (TLR) polymorphisms in African children: common TLR-4 variants predispose to severe malaria. J Commun Dis 2006; 38: 230-245.

25 Faber J, Meyer CU, Gemmer C, Russo A, Finn A, Murdoch C et al. Human toll-like receptor 4 mutations are associated with susceptibility to invasive meningococcal disease in infancy. Pediatr Infect Dis J 2006; 25: 80-81.
26 van Well GT, Sanders MS, Ouburg S, van Furth AM, Morre SA. Polymorphisms in Toll-like receptors 2,4 , and 9 are highly associated with hearing loss in survivors of bacterial meningitis. PLoS One 2012; 7: e35837.

27 Freguja R, Gianesin K, Del Bianco P, Malacrida S, Rampon O, Zanchetta M et al. Polymorphisms of innate immunity genes influence disease progression in HIV-1infected children. Aids 2012; 26: 765-768.

28 Jorgensen MJ, Fisker AB, Erikstrup C, Claesson MH, Benn CS. SNP may modify the effect of vitamin $A$ supplementation at birth on cytokine production in a whole blood culture assay. Br J Nutr 2012; 107: 615-620.

29 Miedema KG, Tissing WJ, Te Poele EM, Kamps WA, Alizadeh BZ, Kerkhof $M$ et al. Polymorphisms in the TLR6 gene associated with the inverse association between childhood acute lymphoblastic leukemia and atopic disease. Leukemia 2012; 26: 1203-1210.

30 Sampath V, Garland JS, Le M, Patel AL, Konduri GG, Cohen JD et al. A TLR5 (g.1174C $>$ T) variant that encodes a stop codon (R392X) is associated with bronchopulmonary dysplasia. Pediatr Pulmonol 2012; 47: 460-468.

31 Plantinga TS, loana $M$, Alonso S, Izagirre N, Hervella M, Joosten LA et al. The evolutionary history of TLR4 polymorphisms in Europe. J Innate Immun 2012; 4: 168-175.

32 Hartel C, Rupp J, Hoegemann A, Bohler A, Spiegler J, von Otte S et al. 159C > T CD14 genotype-functional effects on innate immune responses in term neonates. Hum Immunol 2008; 69: 338-343.

33 Mollen KP, Gribar SC, Anand RJ, Kaczorowski DJ, Kohler JW, Branca MF et al. Increased expression and internalization of the endotoxin coreceptor CD14 in enterocytes occur as an early event in the development of experimental necrotizing enterocolitis. J Pediatr Surg 2008; 43: 1175-1181.

34 Hubacek JA, Stuber F, Frohlich D, Book M, Wetegrove S, Ritter M et al. Gene variants of the bactericidal/permeability increasing protein and lipopolysaccharide binding protein in sepsis patients: gender-specific genetic predisposition to sepsis. Crit Care Med 2001; 29: 557-561.

35 Gu W, Shan YA, Zhou J, Jiang DP, Zhang L, Du DY et al. Functional significance of gene polymorphisms in the promoter of myeloid differentiation-2. Ann Surg 2007; 246: 151-158.

36 von Bernuth $\mathrm{H}$, Picard C, Jin Z, Pankla R, Xiao H, Ku CL et al. Pyogenic bacterial infections in humans with MyD88 deficiency. Science 2008; 321: 691-696.

37 Picard C, Puel A, Bonnet M, Ku CL, Bustamante J, Yang K et al. Pyogenic bacterial infections in humans with IRAK-4 deficiency. Science 2003; 299: 2076-2079.

$38 \mathrm{Ku} \mathrm{CL}$, Picard C, Erdos M, Jeurissen A, Bustamante J, Puel A et al. IRAK4 and NEMO mutations in otherwise healthy children with recurrent invasive pneumococcal disease. J Med Genet 2007; 44: 16-23.

39 Visscher PM, Brown MA, McCarthy MI, Yang J. Five years of GWAS discovery. Am J Hum Genet 2012; 90: 7-24. 